\title{
The relationship between self-management abilities, quality of chronic care delivery, and wellbeing among patients with chronic obstructive pulmonary disease in The Netherlands
}

\author{
This article was published in the following Dove Press journal: \\ International Journal of COPD \\ 24 April 2013 \\ Number of times this article has been viewed
}

Jane Murray Cramm
Anna Petra Nieboer

Erasmus University Rotterdam, Department of Health Policy and Management (iBMG), Rotterdam, The Netherlands

Correspondence: Jane Murray Cramm Erasmus University Rotterdam, Department of Health Policy and Management (iBMG), Burgemeester Oudlaan 50, 3062 PA Rotterdam, Netherlands

$\mathrm{Tel}+3 \mathrm{I} 104089701$

Fax +31 104089094

Email cramm@bmg.eur.nl
Background: This cross-sectional study aimed to identify the relationship between quality of chronic care delivery, self-management abilities, and wellbeing among patients with chronic obstructive pulmonary disease (COPD).

Methods: The study was conducted in 2012 and included 548 (out of 1303; 42\% response rate) patients with COPD enrolled in a COPD care program in the region of Noord-Kennemerland in The Netherlands. We employed a multilevel random-effects model (548 patients nested in 47 healthcare practices) to investigate the relationship between quality of chronic care delivery, self-management abilities, and patients' wellbeing. In the multilevel analyses we controlled for patients' background characteristics and health behaviors.

Results: Multilevel analyses clearly showed a significant relationship between quality of chronic care delivery and wellbeing of patients with COPD $(P \leq 0.001)$. When self-management abilities were included in the equation while controlling for background characteristics, health behaviors, and quality of chronic care delivery, these abilities were found to have a strong positive relationship with patients' wellbeing $(P \leq 0.001)$. Low educational level, single marital status, and physical exercise were not significantly associated with wellbeing when self-management abilities were included in the equation.

Conclusion: Self-management abilities and the quality of chronic care delivery are important for the wellbeing of patients with COPD. Furthermore, self-management abilities acted as mediators between wellbeing and low educational level, single status, and physical exercise among these patients.

Keywords: quality of care, self-management, disease management, COPD, wellbeing, health behaviors

\section{Introduction}

In a time of aging populations, the risk for multiple chronic diseases increases rapidly. ${ }^{1}$ Chronic obstructive pulmonary disease (COPD), which is preventable and treatable, is the leading cause of death from lung disease worldwide and the fourth overall cause of death. ${ }^{2}$ The World Health Organization defines COPD as a lung disease characterized by chronic obstruction of lung airflow that interferes with normal breathing and is not fully reversible. ${ }^{3}$ The prevalence of COPD in The Netherlands is about $12 \% .{ }^{4}$ COPD is a costly disease because it contributes substantially to the volume of emergency department visits and hospitalizations. ${ }^{5}$ Furthermore, COPD patients carry a heavy burden in their daily lives broader than their physical/health condition, 
namely psychological disturbance, psychiatric morbidity, and disability, ${ }^{6,7}$ which is expected to negatively affect their overall wellbeing.

Although advances in treatment have been made, patients with chronic diseases often do not receive optimal care. ${ }^{8}$ For example, research has shown that COPD remains underdiagnosed and undertreated. ${ }^{5,9,10}$ Health service delivery for patients with COPD has focused on acute care and effective management of acute exacerbations and complications to reduce recovery time. Within this "acute care model," the responsibility for problem solving lies with the clinician, and no self-management support or focus on chronic care delivery is provided in the primary care setting. ${ }^{11-13}$ Mild to moderate COPD patients are mostly treated in general practice. ${ }^{14}$ According to recent COPD guidelines, symptoms and airflow obstruction should be monitored regularly within the primary care setting, with the goal of guiding the modification of treatment and early detection of complications. ${ }^{14,15}$ Therefore, COPD patients should be monitored regularly to achieve these goals and to delay disease progression and alleviate its manifestations. ${ }^{16}$ Furthermore, care should be tailored to individual patients' needs with a shared responsibility and comprehensive self-management focused on the needs of the individual COPD patient. ${ }^{1-13,17-20}$ Research showed that higher levels of quality of chronic care delivery resulted in fewer hospital admissions and reduced emergency department visits among COPD patients. ${ }^{21}$ In addition, interventions aimed at COPD patients (eg, self-management interventions), professionals (eg, decision support and training) as well as organizations (eg, implementation of ICT systems) leads to improved effectiveness. $^{22-25}$

Based on these findings, we expect that improving the quality of chronic care delivery in the primary care setting and increasing the self-management abilities of COPD patients may allow them to better maintain their overall wellbeing. High quality chronic care delivery calls for a comprehensive approach to chronic care management with multidisciplinary teams to support the individual overtime and take responsibility for patients' wellbeing with general practitioners. Improved patient outcomes have resulted from holistic and patient-centered programs that offer self-management support services. ${ }^{20}$ Most of these self-management interventions focus mainly on teaching patients to effectively deal with their chronic disease. ${ }^{26-28}$ Patients with COPD, however, must manage their chronic condition on a daily basis (such as by taking medication, exercising, eating healthily, and quitting smoking). As a result, day-to-day care constitutes a fundamental part of chronic care, in which patients' selfmanagement abilities are indispensible. ${ }^{27}$ Therefore, in addition to focusing on disease-related self-management abilities, interventions aimed at the self-management of overall wellbeing may be needed. ${ }^{29,30}$ As many chronically ill patients suffer from a combination of problems in multiple life domains, they may benefit more from self-management interventions that provide them with a general repertoire for dealing with different kinds of problems, rather than from interventions focusing solely on disease-related problems..$^{29,31}$

We lack knowledge of self-management abilities required to maintain overall wellbeing among patients with COPD, and thus, in this article, we focus on this knowledge instead of only investigating disease specific outcomes. Additionally, the relationship between the quality of chronic care delivery and the wellbeing of these patients in the primary care setting is under-researched. Thus, this study aimed to identify the relationship between quality of chronic care delivery, self-management abilities, and wellbeing of COPD patients. In the following analyses, we will control for background characteristics (age, gender, marital status, and educational level) and health behaviors (physical exercise and smoking).

\section{Methods}

This cross-sectional study was conducted in May 2012 and included 548 (out of 1303; 42\% response rate) patients with COPD. These patients had recently enrolled in a newly implemented COPD care program called "Kennemer Lucht" and received primary care at one of the 47 participating healthcare practices in the Noord-Kennemerland region of The Netherlands. This program started in March 2012 and implemented several interventions to improve care for COPD patients. Examples of implemented interventions for COPD patients are: patient education, counseling on treatment compliance, coping strategies, lifestyle advices (on healthy diet, drinking, smoking, and exercise), medical treatment according to clinical guidelines and use of flowcharts, regular follow-up of patients, and regular consultation/coordination with hospital care. The COPD-program Kennemer Lucht included all patients diagnosed with COPD (Global Initiative for Chronic Obstructive Lung Disease stages 1-4) who are currently in GP care. No additional inclusion criteria were applied. All patients received a questionnaire at home via mail. A few weeks later, a reminder notice was sent to nonrespondents. Another few weeks later, a second reminder with 
another copy of the questionnaire was sent. The study was approved by the ethics committee of the Erasmus University Medical Centre of Rotterdam in April 2012 (MEC-2012143).

\section{Measures}

Wellbeing was measured with the 15 -item version of the Social Production Function Instrument for the Level of Wellbeing (SPF-IL; Nieboer et al 2005). ${ }^{31}$ The SPF-IL has been proven to be a reliable instrument for the assessment of wellbeing. ${ }^{31-35}$ This scale measures levels of physical (comfort, stimulation) and social (behavioral confirmation, affection, status) wellbeing. Examples of questions are: "Do people pay attention to you?" (affection), "Do you feel useful to others?" (behavioral confirmation), "Are you known for the things you have accomplished?" (status), "In the past few months have you felt physically comfortable?" (comfort), and "Do you really enjoy your activities?" (stimulation). Answers are given on a 4-point scale ranging from never (1) to always (4), with higher mean scores indicating greater wellbeing. Cronbach's alpha of the SPF-IL was 0.86, indicating good reliability.

Patients' assessments of care were measured with the 20-item Patient Assessment of Chronic Illness Care (PACIC) questionnaire, which uses a 5-point response scale ranging from "almost never" to "almost always". ${ }^{36}$ Examples of questions are: "When I received care for my chronic illness over the past 6 months I was asked for my ideas when we made a treatment plan", "Satisfied that my care was well organized", "Asked how my chronic illness affects my life", and "Asked how my visits with other doctors were going". The PACIC has been proven to be a reliable and valid tool for measuring the quality of chronic care delivery from the patient's perspective, based on his or her experience. The scale's internal consistency was 0.94 . Scores ranged from 1 to 5 , with higher scores representing a higher quality of chronic care delivery.

Patients' self-management abilities were measured with the Self-Management Ability Scale Short version (SMAS-S). ${ }^{33}$ This instrument assesses a broad repertoire of self-management abilities to maintain one's wellbeing. The taking initiative, investing, self-efficacy, variety, and multifunctionality subscales are related to the physical and social dimensions of wellbeing, and the ability to have a positive frame of mind subscale is considered to be a more general cognitive frame. ${ }^{37}$ Examples of self-management abilities are self-efficacy and taking initiatives (ie, being instrumental or self-motivating in enhancing health and wellbeing). The scale's internal consistency was 0.91 . Average self-management ability scores ranged from 1 to 6 , with higher scores indicating better self-management abilities.

Physical activity was assessed by asking respondents on how many days per week they were physically active (eg, sports activities, exercise, walking, housecleaning, work in the garden) for at least 30 minutes. Current smoking was assessed with a "yes" or "no" question. Education was assessed on six levels ranging from (1) no school or some primary education ( $\leq 7$ years) to (6) completion of a university degree ( $\geq 18$ years). We dichotomized this item into (1) low educational level (no school/some primary education or lower technical/vocational education) and (0) (higher than lower technical/vocational education). We further asked respondents to report their marital status, gender, and age.

\section{Statistical analyses}

We used descriptive statistics to describe the study population. Univariate analyses were used to assess associations among background characteristics, health behaviors (physical exercise and smoking), quality of chronic care delivery, self-management abilities, and wellbeing. We employed a multilevel random-effects model (548 patients nested in 47 healthcare practices) to investigate the relationship between quality of chronic care delivery, self-management abilities, and wellbeing of patients with COPD. In the analyses we controlled for patients' background characteristics and health behaviors. Independent variables were all standardized in the multilevel analyses. Model 1 includes background characteristics, health behaviors (physical exercise and smoking) and quality of chronic care delivery. Self-management abilities were added in Model 2 to investigate the mediating role of selfmanagement abilities on the relationship between wellbeing, patient characteristics, and health behaviors. Results were considered statistically significant when two-sided $P$ values were $\leq 0.05$ (SPSS ver. 20, mixed models option; IBM Corporation, Armonk, NY, USA).

\section{Results}

Table 1 displays descriptive statistics for the study sample. Of the 548 respondents, $46 \%$ were female, $34 \%$ had a low educational level, and $34 \%$ were single. The mean age of respondents was $69.15 \pm 10.22$ (range, 39-91) years. About one-third (31\%) of the respondents were smokers. Patients performed physical exercise on an average of $4.71 \pm 2.25$ (range, 0-7) days per week. 
Table I Characteristics of patients participating in disease management programs

\begin{tabular}{ll}
\hline & Patients \\
& $\mathbf{n = 5 4 8}$ \\
\hline Mean age (years) & $69.15 \pm 10.22(39-9 I)$ \\
Gender (female) & $46 \%$ \\
Marital status (single) & $34 \%$ \\
Low educational level & $34 \%$ \\
Physical exercise (days per week) & $4.71 \pm 2.25(0-7)$ \\
Smoking & $31 \%$ \\
Quality of chronic care delivery (PACIC) & $2.85 \pm 0.92(I-5)$ \\
Self-management abilities (SMAS-S) & $3.94 \pm 0.7 \mathrm{I}(\mathrm{I}-6)$ \\
Wellbeing (SPF-IL) & $2.77 \pm 0.48(\mathrm{I}-4)$ \\
\hline
\end{tabular}

Note: Data are expressed as mean \pm standard deviation (range) or percentage. Abbreviations: PACIC, Patient Assessment of Chronic Illness Care; SMAS-S, Self-Management Ability Scale Short version; SPF-IL, Social Production Function Instrument for the Level of Wellbeing.

Correlations of independent variables with the wellbeing of patients with COPD are displayed in Table 2. The results of univariate analyses showed that gender $(P \leq 0.01)$, single marital status $(P \leq 0.01)$, low educational level $(P \leq 0.01)$, physical exercise $(P \leq 0.001)$, quality of chronic care delivery $(P \leq 0.001)$, and self-management abilities $(P \leq 0.001)$ were significantly related to patients' wellbeing.

The results of multilevel analyses are displayed in Table 3 . Age $(P \leq 0.001)$ and physical exercise $(P \leq 0.001)$ were positively related to wellbeing, and a negative relationship was found with single marital status $(P \leq 0.05)$ and low educational level $(P \leq 0.01)$. After adjusting for patients' background characteristics and health behaviors, these analyses clearly showed a significant relationship between quality of chronic care delivery and COPD patient wellbeing ( $P \leq 0.001$; Table 3; Model 1). When self-management abilities were included in the equation while controlling for background characteristics, health behaviors, and the quality of chronic care delivery, these abilities were found to be

Table 2 Associations between wellbeing and individual characteristics, health behaviors, quality of chronic care delivery, and self-management abilities

\begin{tabular}{lll}
\hline & Wellbeing & $\mathbf{n}$ \\
\hline Mean age (years) & 0.07 & 530 \\
Gender (female) & $-0.08^{* *}$ & 528 \\
Marital status (single) & $-0.12^{* *}$ & 536 \\
Low educational level & $-0.11^{* *}$ & 536 \\
Physical exercise & $0.18^{* * *}$ & 503 \\
Smoking & -0.08 & 536 \\
Quality of chronic care delivery (PACIC) & $0.29^{* * *}$ & 509 \\
Self-management abilities (SMAS-S) & $0.63^{* * *}$ & 526 \\
\hline
\end{tabular}

Notes: $* * * P \leq 0.001 ; * * P \leq 0.01$; (two-tailed).

Abbreviations: PACIC, Patient Assessment of Chronic Illness Care; SMAS-S, SelfManagement Ability Scale Short version.
Table 3 Relationship between independent variables and wellbeing as assessed by multilevel regression analyses (random intercepts model, $\mathrm{n}=470$ )

\begin{tabular}{lllll}
\hline & \multicolumn{2}{l}{ Model I } & \multicolumn{2}{l}{ Model 2 } \\
\cline { 2 - 5 } & $\boldsymbol{\beta}$ & SE & $\beta$ & SE \\
\hline Constant & 2.78 & 0.20 & 2.77 & 0.20 \\
Mean age (years) & $0.07^{* * *}$ & 0.20 & $0.07^{* * *}$ & 0.20 \\
Gender (female) & -0.02 & 0.20 & -0.03 & 0.20 \\
Marital status (single) & $-0.04^{*}$ & 0.20 & -0.03 & 0.20 \\
Low educational level & $-0.05^{* *}$ & 0.20 & -0.00 & 0.20 \\
Physical exercise & $0.07^{* * *}$ & 0.20 & -0.01 & 0.20 \\
Smoking & -0.01 & 0.20 & -0.01 & 0.20 \\
Quality of chronic care delivery & $0.13^{* * *}$ & 0.20 & $0.09 * * *$ & 0.20 \\
(PACIC) & & & & \\
Self-management abilities (SMAS-S) & & & $0.29 * * *$ & 0.20 \\
\hline
\end{tabular}

Notes: $* * * P \leq 0.001 ; * * P \leq 0.01 ; * P \leq 0.05$ (two-tailed); Listwise deletion of missing cases resulted in the inclusion of 470 cases in the multilevel regression analyses. Abbreviations: PACIC, Patient Assessment of Chronic Illness Care; SMAS-S, SelfManagement Ability Scale Short version; SE, standard error.

strongly and positively related to the wellbeing of patients with COPD ( $P \leq 0.001$; Table 3; Model 2). Low educational level, single marital status, and physical exercise were not significantly associated with wellbeing in analyses including self-management abilities. Thus, self-management abilities acted as mediators between wellbeing and low educational level, single status, and physical exercise among these patients.

\section{Discussion}

This study aimed to identify the relationship between quality of chronic care delivery, self-management abilities, and wellbeing among patients with COPD. Successfully dealing with a chronic condition such as COPD and its impacts on patients' lives is increasingly acknowledged to depend on the ways in which individuals actively manage their disease. ${ }^{38-41}$ After adjusting for patients' background characteristics and health behaviors, these analyses clearly showed the importance of quality of chronic care delivery for the wellbeing of patients with COPD. This finding suggests that patients' perceptions of high quality chronic care delivery improve their wellbeing, which is expected to influence clinical and economic outcomes. ${ }^{42}$

This study additionally showed the importance of selfmanagement abilities for the wellbeing of patients with COPD after controlling for background characteristics, health behaviors, and the quality of chronic care delivery at participating healthcare practices. Furthermore, selfmanagement abilities acted as mediators between wellbeing and low educational level, single status, and physical exercise among these patients. This finding is important 
because less-educated people often lack the necessary resources to effectively self-manage a chronic condition. ${ }^{43}$ Therefore, especially for patients with COPD, who are known to be less educated than those with diabetes and cardiovascular diseases, ${ }^{29}$ self-management abilities should be improved. Furthermore, interventions that aim to enhance self-management abilities to maintain wellbeing may provide a useful addition to more traditional interventions, which are usually focused only on the physical decline associated with chronic conditions and ignore the social context of illness. ${ }^{44,45}$ The ways in which people manage their conditions often vary according to social circumstances and personal experiences. ${ }^{43,46}$ Greenhalgh $^{47}$ therefore argued that the time has come to move beyond such individualistic approaches to more holistic models that consider individuals' social contexts. Our finding that self-management abilities mediate the relationships between wellbeing and marital status and educational level supports this notion. A sociological perspective on disease management that includes the social context of illness may help to contextualize the actions of patients with COPD and increase our understanding of the mechanisms by which patients can be engaged in self-care and their self-management abilities can be enhanced. These efforts, in turn, may improve patients' abilities to successfully manage this condition and cope with its substantial impacts on their lives. ${ }^{48}$

One limitation of this study is that although our results showed that self-management abilities and the quality of chronic care delivery were important for COPD patients' wellbeing, we did not investigate whether interventions aiming to enhance these variables led to improved wellbeing. Further research is necessary to establish causal effects and to investigate the effectiveness of interventions implemented in the COPD program Kennemer Lucht on the improvement of self-management abilities and the quality of chronic care delivery for patients with COPD.

\section{Conclusion}

We can conclude that effectively dealing with COPD is a long-term process of realizing and sustaining wellbeing, which requires proactive self-management and high quality of chronic care delivery. Interventions, such as lifestyle advice, patient education and use of clinical guidelines are expected to improve self-management and quality of chronic care delivery. Additionally, self-management abilities seem to protect for poor wellbeing among COPD patients with low educational level and single status, and poor physical exercise.

\section{Acknowledgments}

This study was funded by PICASSO for COPD foundation. The views are those of the authors.

\section{Disclosure}

The authors report no conflicts of interest in this work.

\section{References}

1. World Health Organization. Global Strategy on Diet, Physical Activity and Health. Geneva: World Health Organization; 2004. Available from: http://www.who.int/dietphysicalactivity/strategy/eb11344/strategy_english_web.pdf. Accessed March 22, 2013.

2. National Institutes of Health, National Heart, Lung, and Blood Institute. Morbidity and Mortality: 2009 Chartbook on Cardiovascular, Lung, and Blood Diseases. 2009. Available from: http://www.nhlbi.nih. gov/resources/docs/2009_ChartBook_508.pdf. Accessed March 22, 2013.

3. http://www.who.int [home page on the Internet]. COPD: Definition. World Health Organization; 2013. Available from: http://www.who.int/ respiratory/copd/definition/en/index.html. Accessed March 22, 2013.

4. Atsou K, Chouaid C, Hejblum G. Variability of the chronic obstructive pulmonary disease key epidemiological data in Europe: systematic review. BMC Med. 2011;9:7.

5. Mannino DM, Homa DM, Akinbami LJ, Ford ES, Redd SC. Chronic obstructive pulmonary disease surveillance - United States, 1971-2000. MMWR Surveill Summ. 2002;51(6):116.

6. Eisner MD, Blanc PD, Yelin EH, et al. Influence of anxiety on health outcomes in COPD. Thorax. 2010;65(3):229-234.

7. Zhang MW, Ho RC, Cheung MW, Fu E, Mak A. Prevalence of depressive symptoms in patients with chronic obstructive pulmonary disease: a systematic review, meta-analysis and meta-regression. Gen Hosp Psychiatry. 2011;33(3):217-223.

8. McGlynn EA, Asch SM, Adams J, et al. The quality of health care delivered to adults in the United States. $N$ Engl J Med. 2003;348(26): 2635-2645.

9. Pleis JR, Lethbridge-Cejku M. Summary health statistics for US adults: National Health Interview Survey, 2006. Washington: National Center for Health Statistics; 2006. Available from: http://www.cdc.gov/nchs/ data/series/sr_10/sr10_235.pdf. Accessed March 22, 2013.

10. Wouters EF. The burden of COPD in The Netherlands: results from the Confronting COPD survey. Respir Med. 2003;97(Suppl C): S51-S59.

11. Bodenheimer T, Wagner EH, Grumbach K. Improving primary care for patients with chronic illness: the chronic care model, Part 2. JAMA. 2002;288(15):1909-1914.

12. Wagner EH, Austin BT, Davis C, Hindmarsh M, Schaefer J, Bonomi A. Improving chronic illness care: translating evidence into action. Health Aff (Millwood). 2001;20(6):64-78.

13. Wagner EH, Austin BT, Von Korff M. Organizing care for patients with chronic illness. Milbank Q. 1996;74(4):511-544.

14. Bellamy D, Bouchard J, Henrichsen S, et al. International Primary Care Respiratory Group (IPCRG) guidelines: management of chronic obstructive pulmonary disease (COPD). Prim Care Respir J. 2006;15(1):48-57.

15. Global Initiative for Chronic Obstructive Pulmonary Disease (GOLD). Global Strategy for the Diagnosis, Management, and Prevention of Chronic Obstructive Pulmonary Disease: Revised 2011. GOLD; 2011. Available from http://www.goldcopd.org/uploads/users/files/ GOLD_Report_2011Dec30.pdf. Accessed on March 22, 2013.

16. Van den Bemt L, Schermer T, Smeele I, et al. Monitoring of patients with COPD: a review of current guidelines' recommendations. Respir Med. 2008;102(5):633-641.

17. Barlow J, Sturt J, Hearnshaw H. Self-management interventions for people with chronic conditions in primary care: Examples from arthritis, asthma and diabetes. Health Educ J. 2002;61(4):365-378. 
18. Barlow J, Wright C, Sheasby J, Turner A, Hainsworth J. Selfmanagement approaches for people with chronic conditions: a review. Patient Educ Couns. 2002;48(2):177-187.

19. Lorig KR, Holman H. Self-management education: history, definition, outcomes, and mechanisms. Ann Behav Med. 2003;26(1):1-7.

20. Rollnick S, Miller WR, Butler CC. Motivational Interviewing in Healthcare: Helping Patients Change Behavior. New York: The Gilford Press; 2008.

21. Adams SG, Smith PK, Allan PF, Anzueto A, Pugh JA, Cornell JE. Systematic review of the chronic care model in chronic obstructive pulmonary disease prevention and management. Arch Intern Med. 2007;167(6):551-561.

22. Lemmens KMM. Improving Chronic Care: Developing and Testing Disease-Management Interventions Applied in COPD Care [PhD thesis]. Rotterdam: Erasmus University Rotterdam; 2009.

23. Lemmens KM, Nieboer AP, Rutten-Van Mölken MP, et al. Bottom-up implementation of disease-management programmes: results of a multisite comparison. BMJ Qual Saf. 2011;20(1):76-86.

24. Steuten LM, Lemmens KM, Nieboer AP, Vrijhoef HJ. Identifying potentially cost effective chronic care programs for people with COPD. Int J Chron Obstruct Pulmon Dis. 2009;4:87-100.

25. Cramm JM, Rutten-Van Mölken MP, Nieboer AP. The potential for integrated care programmes to improve quality of care as assessed by patients with COPD: early results from a real-world implementation study in The Netherlands. Int J Integr Care. 202;12:1-7.

26. Glasgow RE, Toobert DJ, Hampson SE, Strycker LA. Implementation, generalization and long-term results of the "choosing well" diabetes selfmanagement intervention. Patient Educ Couns. 2002;48(2):115-122.

27. Lorig K, Laurin J, Holman HR. Arthritis self-management: a study of the effectiveness of patient education for the elderly. Gerontologist. 1984;24(5):455-457.

28. Schreurs KM, Colland VT, Kuijer RG, De Ridder DT, Van Elderen T. Development, content, and process evaluation of a short selfmanagement intervention in patients with chronic diseases requiring self-care behaviours. Patient Educ Couns. 2003;51(2):133-141.

29. Cramm JM, Nieboer AP. Self-management abilities, physical health and depressive symptoms among patients with cardiovascular diseases, chronic obstructive pulmonary disease, and diabetes. Patient Educ Couns. 2012;87(3):411-415.

30. Frieswijk N, Steverink N, Buunk BP, Slaets JP. The effectiveness of a bibliotherapy in increasing the self-management ability of slightly to moderately frail older people. Patient Educ Couns. 2006; 61(2):219-227.

31. Nieboer A, Lindenberg S, Boomsma A, Van Bruggen AC. Dimensions of wellbeing and their measurement: the SPF-IL scale. Soc Ind Res. 2005;73:313-353.

32. Cramm JM, Hartgerink JM, Steyerberg EW, Bakker TJ, Mackenbach JP, Nieboer AP. Understanding older patients' self-management abilities: functional loss, self-management, and wellbeing. Qual Life Res. 2012. 2013;22(1):85-92.
33. Cramm JM, Strating MM, de Vreede PL, Steverink N, Nieboer AP. Validation of the self-management ability scale (SMAS) and development and validation of a shorter scale (SMAS-S) among older patients shortly after hospitalisation. Health Qual Life Outcomes. 2012;10:9.

34. Cramm JM, van Dijk HM, Nieboer AP. The importance of perceived neighborhood social cohesion and social capital for the wellbeing of older adults in the community. Gerontologist. 2013;53(1):142-152.

35. Cramm JM, Hartgerink JM, de Vreede PL, et al. The relationship between older adults' self-management abilities, well-being, and depression. Eur J Ageing. 2012;9(4):353-360.

36. Glasgow RE, Wagner E, Schaefer J, Mahoney L, Reid R, Greene S. Development and validation of the Patient Assessment of Chronic Illness Care (PACIC). Med Care. 2005;43(5):436-444.

37. Schuurmans H, Steverink N, Frieswijk N, Buunk BP, Slaets JP, Lindenberg S. How to measure self-management abilities in older people by self-report. The development of the SMAS-30. Qual Life Res. 2005;14(10):2215-2228.

38. Gijsen R, Hoeymans N, Schellevis FG, Ruwaard D, Satariano WA, van den Bos GA. Causes and consequences of comorbidity: a review. J Clinic Epidemiol. 2001;54(7):661-674.

39. Kempen GI, Jelicic M, Ormel J. Personality, chronic medical morbidity, and health-related quality of life among older persons. Health Psychol. 1997;16(6):539-546.

40. Kempen GI, Ormel J, Brilman EI, Relyveld J. Adaptive responses among Dutch elderly: the impact of eight chronic medical conditions on health-related quality of life. Am J Public Health. 1997;87(1):38-44.

41. Steverink N, Lindenberg S, Slaets JP. How to understand and improve older people's self-management of wellbeing. Eur J Ageing. 2005; 2(4):235-244.

42. Nutting PA, Dickinson WP, Dickinson LM, et al. Use of chronic care model elements is associated with higher-quality care for diabetes. Ann Fam Med. 2007;5(1):14-20.

43. Lindsay $\mathrm{S}$. The influence of childhood poverty on the self-management of chronic conditions in later life. Res Sociol Health Care. 2009; 27:161-183.

44. Carr J, Moffett M. The impact of social deprivation on chronic back pain outcomes. Chronic Illn. 2005;1(2):121-129.

45. Kendall E, Rogers A. Extinguishing the social? State sponsored self-care policy and the chronic disease self-management program. Disabil Soc. 2007;22(2):129-143.

46. Lindsay S. How and why the motivation and skills to self-manage coronary heart disease are socially unequal. Res Sociol Health Care. 2008;26:17-39.

47. Greenhalgh T. Patient and public involvement in chronic illness: beyond the expert patient. BMJ. 2009;338:b49.

48. Lindsay S, Vrijhoef HJM. A sociological focus on 'expert patients'. Health Sociol Rev. 2009;18:139-144.
International Journal of COPD

\section{Publish your work in this journal}

The International Journal of COPD is an international, peer-reviewed journal of therapeutics and pharmacology focusing on concise rapid reporting of clinical studies and reviews in COPD. Special focus is given to the pathophysiological processes underlying the disease, intervention programs, patient focused education, and self management protocols.
Dovepress

This journal is indexed on PubMed Central, MedLine and CAS. The manuscript management system is completely online and includes a very quick and fair peer-review system, which is all easy to use. Visit http://www.dovepress.com/testimonials.php to read real quotes from published authors. 